\title{
RISK FACTORS OF PROTEIN CALORIE MALNUTRITION UNDER FIVE YEARS; TERTIARY CARE HOSPITALS, PESHAWAR
}

\author{
Mazhar Khan ${ }^{1}$, Irum $\mathrm{Naz}^{2}$, Farida Sherazi ${ }^{3}$, Rifayatullah Afridi ${ }^{4}$, Aneela \\ Ambreen $^{5}$, Dure Nayab 6
}

\section{ABSTRACT:}

\section{OBJECTIVES:}

The purpose of this study was to know about the risk factors of malnutrition and the incidence of risk factors among known cases of malnutrition admitted in tertiary care hospitals of Peshawar.

\section{METHODOLOGY:}

A descriptive cross-sectional study was done. Study was conducted in tertiary care hospitals of Peshawar from March 2019 to July 2019. Study included 100 patients of protein calorie malnutrition less than five years of age. Internationally recognized Gomez classification was used to label patient as malnourished. Risk factors of primary malnutrition including socioeconomic status, ignorance of weaning, poverty, lack of immunization and primary care, maternal illiteracy and risk factors of secondary malnutrition including infections, congenital diseases, malabsorptive disorders and metabolic disorders were assessed. Data was collected through a questionnaire. Tables and graphs were used to determine the frequency of risk factors for protein calorie malnutrition.

\section{RESULTS:}

Among 100 patients of PCM 59 were male and 41 were females. After assessment of both genders, risk factors that show close association with protein calorie malnutrition were low socioeconomic status, maternal illiteracy, lack of family planning, poor weaning and repeated infections. Among these risk factors the most frequently observed risk factors for protein calorie malnutrition were low socioeconomic status and repeated infections.

\section{CONCLUSION:}

Low socioeconomic condition and repeated infections are the leading cause of protein calorie malnutrition.

KEYWORDS: Malnutrition, Gomez Classification, Frequency, Risk Factors

How to cite this article:

Khan M, Naz I, Sherazi F, Afridi R, Ambreen A, Nayab D. Risk factors of protein calorie malnutrition under five years; tertiary care hospitals, Peshawar. J Gandhara Med Dent Sci. 2020;6(2):3-9. doi:

10.37762/jgmds.6-2.92 


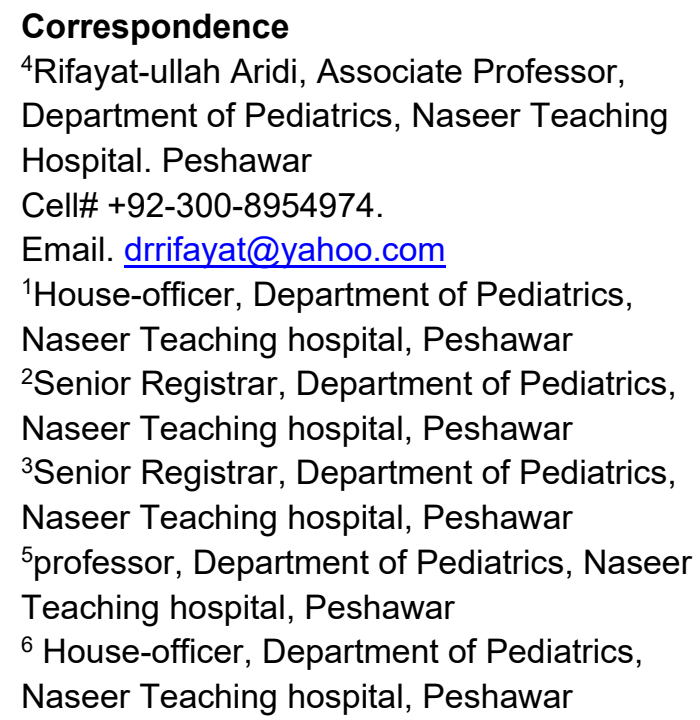

${ }^{4}$ Rifayat-ullah Aridi, Associate Professor, Department of Pediatrics, Naseer Teaching Hospital. Peshawar

Cell\# +92-300-8954974.

Email.drrifayat@yahoo.com

${ }^{1}$ House-officer, Department of Pediatrics,

Naseer Teaching hospital, Peshawar

${ }^{2}$ Senior Registrar, Department of Pediatrics,

Naseer Teaching hospital, Peshawar

${ }^{3}$ Senior Registrar, Department of Pediatrics,

Naseer Teaching hospital, Peshawar

${ }^{5}$ professor, Department of Pediatrics, Naseer

Teaching hospital, Peshawar

${ }^{6}$ House-officer, Department of Pediatrics,

Naseer Teaching hospital, Peshawar

\section{INTRODUCTION:}

Pathological condition subsequent from absolute or relative deficit of one or more essential nutrients is known as malnutrition. This condition has mild, moderate and severe degrees. Protein calorie malnutrition or protein energy malnutrition has been classified into Marasmus, Kwashiorkor and Marasmic Kwashiorkor. Marasmus means severe wasting; Kwashiorkor is characterized by edema and Marasmic Kwashiorkor means severe wasting plus edema. When there is an imbalance between food intake and actual metabolic needs, various symptoms of protein calorie malnutrition occur which if remained as such, leads to serious health problems and even deaths ${ }^{1}$. There are various causes of protein calorie malnutrition. Causes of primary malnutrition include failure of lactation, ignorance of weaning, poverty, lack of immunization and primary care, and lack of family planning. Factors that are responsible for secondary malnutrition are repeated infections, worm's infestation, congenital diseases, malabsorption and metabolic disorders. Most of these risk factors affect children under 5 years of age ${ }^{1}$. According to $\mathrm{WHO}, 175$ million children in the developing world are malnourished as shown by low weight for age ${ }^{1}$. It is recognized that most deaths among children in the developing world is associated with malnutrition ${ }^{1,2}$. Paediatric age is a time of active growth in childhood there is increase in physical size, mental, emotional, sexual maturation and psychological development. Growth of a child depends on enough nutrition and includes major transformations from birth to adulthood. Body uses carbohydrates, fat and proteins as a source of energy. Malnutrition can be caused by less intake of energy and nutrients ${ }^{3}, 4$. Undernourishment has a direct effect on the physical and mental health of a child leading to poor developmental achievements and poor school performance. It has been assessed that thirty percent of children are under the age of five in the world are moderately or severely stunted whereas nineteen percent are malnourished ${ }^{5}$. In Asia the incidence of stunned children is almost half, eight percent offspring under five years of age are wasted, and $2 / 3$ of them belongs to Asia ${ }^{6}$. Health, socioeconomic development of children and the dynamic prospective of the society are the problems caused by malnutrition. In contrast to other developing countries, Pakistan has one of the highest prevalence of malnutrition ${ }^{7}$. National Nutrition Survey reported that thirty three percent of children were underweight, forty-four percent were stunted, fifteen percent were wasted, and fifty percent had iron deficiency (anaemia). The incidence of malnutrition has decreased from last two decades in Pakistan ${ }^{8}, 9$. Since the cases of protein calorie malnutrition has been noted to increase in number among 
admitted patients in paediatric wards in tertiary care hospitals of Peshawar. The purpose of this study was to know about the risk factors and to check that which risk factor is the major contributing factor for such an increase in protein calorie malnutrition in children.

\section{METHODOLOGY:}

A descriptive cross-sectional study was done in tertiary care hospitals of Peshawar from March 2019 to July 2019. Gomez criteria (an internationally recognized criteria) mentioned in a research on Protein Calorie Malnutrition was used to label a patient malnourished. According to Gomez, patient-having weight less than $90 \%$ of the expected weight for age will be labelled as malnourished. In this criterion standard weight charts assess weight at various ages. If weight is less than expected for that age, then child is considered malnourished. Cases labelled as protein calorie malnutrition according to Gomez classification were included in the study. Children who were handicapped or having other genetic physical disability were excluded from the study. A proper questionnaire containing questions regarding sociodemographic factors and other risk factors was used. Questionnaire was filled after verbal consent from the parents of 100 patients. Inquiries were made regarding different risk factors of protein calorie malnutrition including socioeconomic status, ignorance of weaning, poverty, lack of immunization and primary care, illiteracy, repeated infections, congenital diseases, malabsorptive disorders and metabolic disorders. Anthropometric data like length or height was checked using inch tape, infant meter and stadiometer respectively. Anthropometric data was taken with least possible clothes on patient's body. Germen scale and baby weighing machine pan type was used to measure the weight. Same quality of measuring machine was used in all hospitals. Maternal BMI was also calculated according to standard formulae to check the risk factor of low maternal BMI contributing to protein calorie malnutrition in children. Data was analysed and presented in form of tables and graphs.

\section{RESULTS:}

100 patients were included among which $59 \%$ were males, while $41 \%$ were female. $54 \%$ of the patients were below the age of 2.5 years. After analysis of the data, the major risk factors responsible for the development of protein calorie malnutrition were maternal illiteracy, low socioeconomic status, inadequate breast feeding or poor weaning and history of repeated infections.

Table 1: Baseline and Demographics

\begin{tabular}{|l|c|c|}
\hline \multirow{3}{*}{ Gender } & Male & $59 \%$ \\
\cline { 2 - 3 } Age & Female & $41 \%$ \\
\hline \multirow{3}{*}{ Maternal Education } & $<2.5$ & $54 \%$ \\
\hline $\begin{array}{l}\text { Socioeconomic Status } \\
\text { (Monthly Income) }\end{array}$ & $>2.5$ & $46 \%$ \\
\cline { 2 - 3 } & Unable to write and read name & $90 \%$ \\
\cline { 2 - 3 } & Able to write and read name & $10 \%$ \\
\cline { 2 - 3 } & Less than 20K & $88 \%$ \\
\hline
\end{tabular}


Among the 100 patients, $90 \%$ of the children were from illiterate families. Second most frequent risk factor for protein calorie malnutrition in our study was history of repeated infections. It was asked from the mother regarding repeated infections especially gastroenteritis and respiratory, and admission for those illnesses patient who were having positive history of admissions due to infections were labelled as having this risk factor which was positive in $89 \%$ of cases.

Table 2: Percentage of Different Risk Factors Contributing to Protein Calorie Malnutrition

\begin{tabular}{|l|c|c|}
\hline \multicolumn{1}{|c|}{ Risk factor } & Present in \% of patients & Absent in \% of patients \\
\hline Poor weaning & $65 \%$ & $35 \%$ \\
\hline Poor breast feeding & $72 \%$ & $28 \%$ \\
\hline Low maternal BMI & $69 \%$ & $31 \%$ \\
\hline History of repeated infection & $89 \%$ & $11 \%$ \\
\hline Worm infestation & $51 \%$ & $49 \%$ \\
\hline
\end{tabular}

Third common risk factor was low socioeconomic status, which was present in $88 \%$ of patients. Fourth most common risk factor was poor breastfeeding at $72 \%$ and poor weaning present in $65 \%$ of patient. Low maternal BMI was present in $69 \%$ of cases. Worm infestation was also more common and was present in $51 \%$ of the patients.

Figure 1: Percentage of Absence or Presence of Risk Factors

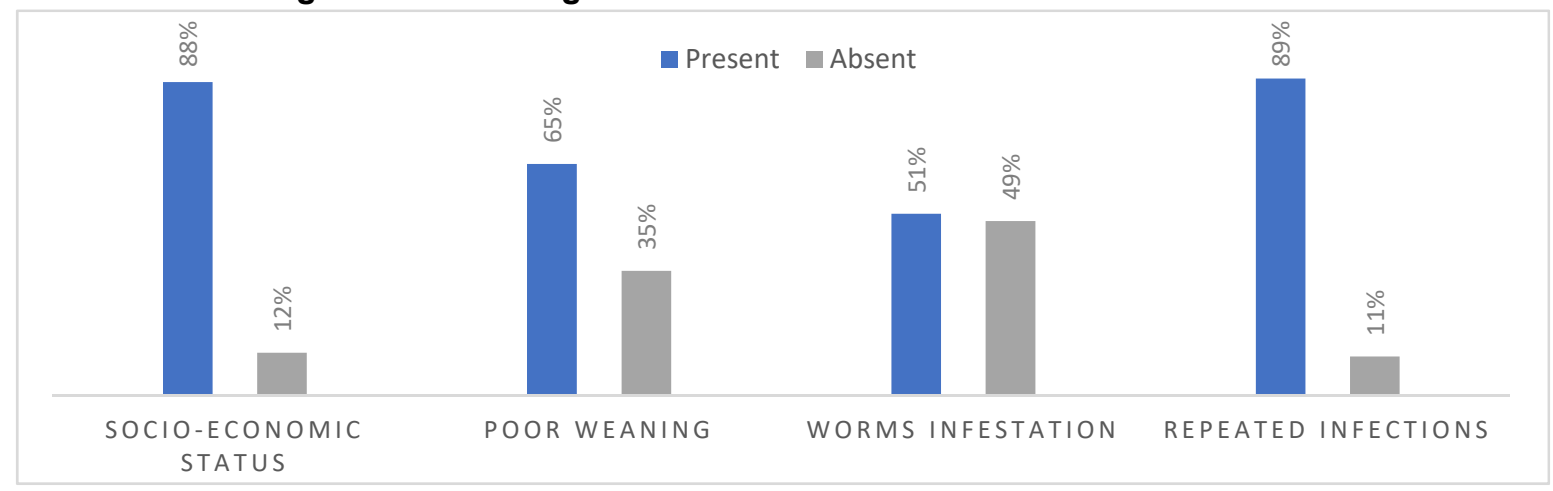

Figure 2: Percentage of Absence or Presence of Risk Factors Among Mother

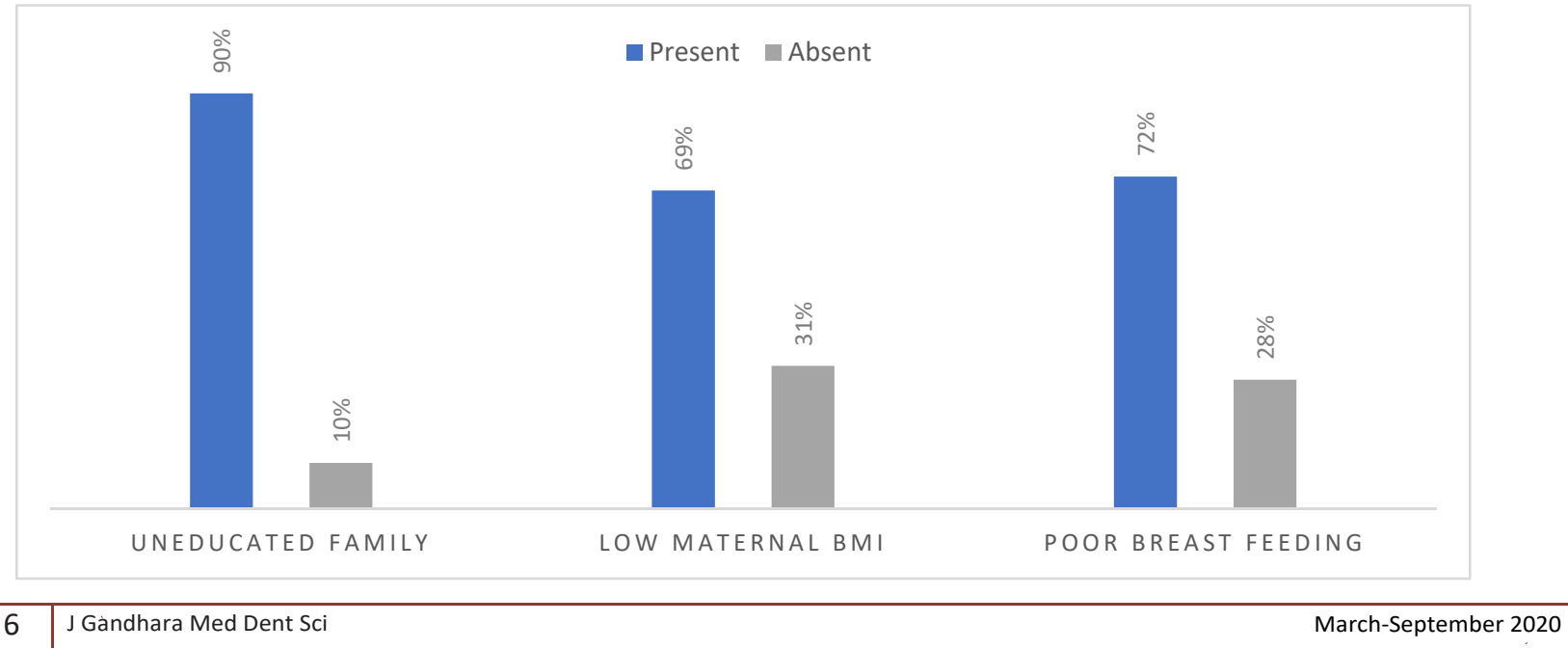




\section{DISCUSSION:}

Studies had shown that nutritional deficiencies not only affect physical and mental development significantly but also cause the mortality of 14 million children in the world each year. Women and children are the most susceptible groups and are more prone to malnutrition. Different factors such as poverty, poor literacy, unfair nutrition beliefs, deficient nourishment, and occurrence of infectious and parasitic diseases are among the factors precipitating malnutrition among these people ${ }^{10}$. A study was done in Ethiopia in 2017 to know about the prevalence of malnutrition and associated factors. In this study the results were that the prevalence of malnutrition among rural children in Ethiopia was $48.5 \%$. Age of the children, preceding birth interval, educational status of mother, wealth status, and region were factors independently associated with nutritional status of children in rural Ethiopia ${ }^{11}$. Another study that was done in 2010 in Iran $^{12}$ prevalence of malnutrition in under 6-year olds in South Khorasan and the results were that prevalence of underweight and stunting had a significant relationship to mother's residence, education and job, so that education level was in inverse proportion to malnutrition. This was more tangible in the case of employed mothers compared to housewives; and more in rural children rather than in urban subjects. In various studies, illiteracy and low education of parents have had a relationship to the malnutrition of children ${ }^{13}$. This difference is due to the two factors of higher knowledge of literate parents and higher income of families with higher education compared to the illiterate ones regarding children's nutrition. Obviously, income is one of the important factors providing the access to health care, education, and nutrition facilities as the factors precipitating malnutrition. Besides, knowledge together with enough income can improve nutritional status of the family ${ }^{14}$. Another study showed that occurrence of different types of malnutrition among children whose mothers were employed was lower than children with housewife mothers ${ }^{15-17}$. The effective factors here were also the two phenomena of knowledge and income. Regarding the age, the present study showed that underweight and stunting were higher in two-year olds in comparison with over-two-year olds, which is in accord with the study done in Bam and the one carried out in Golestan ${ }^{18}$. This shows that children under two are more prone to malnutrition and require more nutritive care and attention ${ }^{19}$. The results of this study show that malnutrition is a severe problem of under five-year-old children in tertiary care hospitals of Peshawar. In this study the major risk factor for malnutrition is illiteracy. About $90 \%$ of the parents of malnourished patients were uneducated. Second on the list was low socioeconomic status as discussed earlier in results. Other more frequently found risk factors were poor weaning, poor breastfeeding, repeated infections and worm's infestation. We observed that 
due to illiteracy parents especially mother don't know about the proper balanced diet and due to low socioeconomic status children couldn't get quality food.

\section{CONCLUSION:}

Since there is high prevalence of malnutrition among children in tertiary care hospitals of Peshawar it is necessary to promote the knowledge and education of parents; particularly mothers and social-economic, health, and nutritional status of families. This is mainly the responsibility of the authorities to seek solutions to such problems. Beside this a proper campaign should be started to deworm children, to provide a proper medical care for infections and illnesses and promoting and encouraging breast-feeding.

\section{REFERENCES:}

1. Stevens GA, Finucane MM, Paciorek CJ, Flaxman SR, White RA, Donner $\mathrm{AJ}$, et al. Trends in mild, moderate, and severe stunting and underweight, and progress towards MDG 1 in 141 developing countries: a systematic analysis of population representative data. Lancet. 2012;380(9844):824-34.

2. United Nation International Children's Emergency Fund (UNICEF). Levels and trends in child malnutrition [Internet]. 2015.

3. Di Cesare M, Bhatti Z, Soofi SB, Fortunato L, Ezzati M, Bhutta ZA. Geographical and socioeconomic inequalities in women and children's nutritional status in Pakistan in 2011: an analysis of data from a nationally representative survey. Lancet Glob Health. 2015;3(4): e229-39.
4. Planning Commission, Government of Pakistan, Pakistan Institute of Development Economics. National Nutrition Survey. Pakistan Institute of Development Economics; Islamabad, Pakistan: 2018.

5. Endris N, Asefa $H$, Dube L. Prevalence of malnutrition and associated factors among children in rural Ethiopia. BioMed Res Int. 2017; 2017:1-6.

6. Minaie M, Jazayeri A, Amiri M, Heidari $\mathrm{GH}$, Anareki A. Anthropometric evaluation of the nutritional status in 0-36-month-old children in rural areas of Bushehr province. J Bushehr Univ Med Sci. 1998; 1:232-40.

7. Mian RM, Ali M, Ferroni PA, Underwood $P$. The nutritional status of school-aged children in an urban squatter settlement in Pakistan. Pak J Nutr. 2002;1(3):121-3.

8. Arif GM. Child health and poverty in Pakistan. Pak Development Rev. 2004:211-38.

9. Akhtar S, Ahmed A, Ahmad A, Ali Z, Riaz $M$, Ismail $T$. Iron status of the Pakistani population-current issues and strategies. Asia Pacific J Clin Nutr. 2013;22(3):340-47.

10. Noorsalehi E, Ghalleh Zari S, Aminian $M$. Determination of prevalence rate of protein-energy malnutrition in children under 5 in urban and rural areas of Guilan province. Uni Med Sci. 1997;24(23):6.

11. Yalew BM. Prevalence of malnutrition and associated factors among children age 6-59 months at Lalibela town administration, North WolloZone, Anrs, Northern Ethiopia. J Nutr Disorders Ther. 2014;4(132):114.

12. Sharifzadeh G, Mehrjoofard H, Raghebi S. Prevalence of malnutrition in under 6-year olds in South Khorasan, Iran. Iran J Pediatr. 2010;20(4):435-41. 
13. Babar NF, Muzaffar R, Khan MA, Imdad S. Impact of socioeconomic factors on nutritional status in primary school children. J Ayub Med Coll Abbottabad. 2010;22(4):15-8.

14. Nojomi N, Kafashi A, Najmabadi $\mathrm{SH}$. Study of frequency of malnutrition risk factors in under 5 years children in Karaj, 2001-2002. Razi J Med Sci. 2003;10(33):123-30.

15. Ergin F, Okyay P, Atasoylu G, Beser E. Nutritional status and risk factors of chronic malnutrition in children under five years of age in Aydin, a western city of Turkey. Turk J Pediatr. 2007;49(3):283-9.

16. Cui $Y$, Yang L, Zhao $Y X, W u Q$, Tian XB. Study on status of nutrition in children under three years old in rural area in China. Chinese $\mathrm{J}$ Epidemiology. 2008;29(3):230-4.
17. Jafarinia $\mathrm{N}, \quad$ Faraz $\mathrm{A}$, Akhoundzadeh SH, Gahgaei Z. Investigation of the range and effective factors on protein-energy malnutrition based on nutritional classification of rural zone of Arak in children less than five years. Arak Med Univ J. 2003;6(2):7-13.

18. Sayari AA, Sheykh AR, Naghavi RM, Abdollahi Z, Kolahdooz F, Jamshid BE. Surveying different types of malnutrition in children under 5 years old in urban and rural areas, Iran, 1998. Res Bulletin Med Sci (Pejouhandeh). 2001;5(4):409-16.

19. Rice AL, Sacco L, Hyder A, Black RE. Malnutrition as an underlying cause of childhood deaths associated with infectious diseases in developing countries. Bulletin World Health Organization. 2000;78(10):1207-21.

\section{CONTRIBUTORS}

1. Mazhar Khan - Data Analysis/Interpretation; Drafting Manuscript

2. Irum Naz - Concept \& Design; Drafting Manuscript

3. Farida Sherazi - Critical Revision

4. Rifayatullah Afridi - Final Approval

5. Aneela Ambreen - Supervision

6. Dure Nayab - Data Acquisition

LICENSE: JGMDS publishes its articles under a Creative Commons Attribution Non-Commercial Share-Alike license (CC-BY-NC-SA 4.0) COPYRIGHTS: Authors retain the rights without any restrictions to freely download, print, share and disseminate the article for any lawful purpose. It includes scholarly networks such as Research Gate, Google Scholar, LinkedIn, Academia.edu, Twitter, and other academic or professional networking sites. 